\title{
Prevalence Rate of Alcohol Use and Its Associated Factors among Undergraduate Students of Jigjiga University
}

\author{
Desalegn Shiferaw ${ }^{1 *}$, Tadele Kinati ${ }^{2}$, Gamachu Fufa ${ }^{3}$ and Lemessa Assefa ${ }^{4}$ \\ ${ }^{1}$ Epidemiology and Biostatistics Unit, Department of Public Health, College of Medicine and Health Sciences, Jigjiga University, Africa \\ ${ }^{2}$ Department of Nursing, College of Medicine and Health Sciences, Jigjiga University, Africa \\ ${ }^{3}$ Department of Sociology, College of Social sciences and Humanity, Jigjiga University, Africa \\ ${ }^{4}$ Reproductive and Nutrition Unit, Department of Public Health, College of Medicine and Health Sciences, Jigjiga University, Africa
}

Submission: September 07, 2017; Published: October 13, 2017

*Corresponding author: Desalegn Shiferaw, Department of Public Health, Jigjiga University, Ethiopia, Africa, Tel: 251920438525 ;

Email: latisenako@gmail.com

Abstract

Background: Use of substances such as alcohol, khat leaves (Catha edulis) and tobacco has become the rising major public health and socio-economic problems worldwide. This study was aimed to assess alcohol use among undergraduate students of Jigjiga University in Ethiopia.

Methods: A cross sectional study design was used and the study population was students from selected departments. The sample size was calculated by use of single population proportion formula. Accordingly, the calculated sample size was 648 after multiplying by design effect of 1.5 and adding 10\%for non-response rate. Descriptive statistics, binary and multivariable logistic regressions was employed. Adjusted Odds Ratios together with corresponding 95\% confidence intervals was used to interpret the findings.

Result: This study found 164(27.3\%) alcohol users from the total of 600 respondents who filled the questionnaire. The odds of drinking alcohol was higher among senior students; those at $3 \mathrm{rd}$ year with AOR $=5(95 \% \mathrm{CI}=2.13,10.25)$, those at 4 th year with $\mathrm{AOR}=4.92(95 \% \mathrm{CI}=1.98$, $12.14)$, compared with their junior 2 nd year students. Male sex (AOR $=2.1295 \% \mathrm{CI}=1.89,6.69)$ and use of other drugs $(11.55(3.28,40.75)$ were also positively associated to the use of alcohol.

Keywords: Alcohol; Prevalence; University students

\section{Introduction}

Alcohol drinking has become one of the rising major public health and socio-economic problems worldwide [1] and it is one of the most important risks taking behavior among adolescents and young population in colleges and Universities [1]. Recent trends indicate that the use of alcohol has dramatically increased particularly in developing countries [1]. It is estimated that $9 \%$ of the global population aged 12 or older are classified with dependence on psychoactive substances such as alcohol [2] and it becomes a growing concern among students [3].

Studies indicate that substance use among Ethiopian adolescents is considerably rising [4]. Nowadays, alcohol is widely consumed among high school and college students in Ethiopia [4]. Of the young segment of the Ethiopian population, college and university students are the most at risk of using alcohol [4]and entering University often leads to new opportunities, independence from family control, self-decision making, and peer-pressures to use or abuse alcohol. The use of alcohol among adolescents can be harmful, leading to decreased academic performance, increased risk of contracting HIV and other sexually transmitted diseases, or other psychiatric disorders such as lethargy, hopelessness and insomnia [2].

The six month prevalence rate of alcohol consumption was seventy percent and 28 percent were identified as regular users [5]. There is a strong link between khat chewing and excessive alcohol consumption, and it is believed to be one of the factors associated with unprotected risky sexual behavior, predisposing the youth for HIV infection and transmission [6]. The passage from high school to college is commonly marked by an increment in frequency of opportunities for peer interaction and in importance of the role of peer norms. According to a study conducted in United States of America $60 \%$ of individuals within the 21-25 age groups have reported alcohol consumption 30 days prior to the study accordingly, the current study aimed to determine the level of alcohol consumption in the study area [7]. 


\section{Methods and Materials}

Study Setting: This study was conducted in Jigjiga University located in Ethiopia Somali region. The University was established in 2007 and currently having 9 colleges with 14, 640 undergraduate students. Jigjiga is the capital city of the region which is at about $630 \mathrm{~km}$ to the east of Addis Ababa.

Study design and population: Descriptive cross-sectional design was applied in this study. Randomly selected under graduate students of Jigjiga University was recruited during 2013/2014 academic session.

Sample Size Determination and Sampling Procedure: The required sample size was calculated by the single population proportion formula with the assumption of $4 \%$ margin of error (d), $95 \%$ confidence level $(\mathrm{z} \alpha / 2=1.96)$ and $22 \%$ proportion of alcohol consumption taken from study conducted among medical students of Addis Ababa University [8].

$$
n=\frac{\left(z_{\alpha / 2}\right)^{2} \cdot p q}{d^{2}}
$$

Using a design effect of 1.5 , the calculated sample size with $10 \%$ contingency for non-response was 648. A multi stage sampling procedure was applied to select sample of undergraduate students in the University. Initially we stratified the students by their college and three colleges namely college of Medicine and Health sciences, college of social sciences, and college of engineering and technology were randomly selected. The selected colleges were further stratified to departments and departments were selected by simple random sampling. The calculated sample size was proportionally allocated to each department based on the number of their students.

Data Collection Procedure: Self-administered structured questionnaire was used. Data collection was supervised by individuals with previous similar exposure and training was given by the principal investigators on how to create conducive environment for the respondents during data collection and to ensure confidentiality to improve the quality of the data.

Data Analysis: Data were entered using epi data version 3.1 and exported to Statistical Package for Social Science (SPSS) version 16 for further analysis. Following the cleaning, data were exported to SPSS version 16 for analysis. Data analyses were done through Univariate analysis to see the frequencies of the categories under each variable and the corresponding percentage for each category. Bivariable analysis also done to reveal association between the dependent variable (alcohol use) and independent variables like socio-demographic variables and lastly logistic regression was conducted to see the independent effect of the selected independent variables on the status of alcohol use using odds ratio.

Ethical Considerations: The study was reviewed and approved by the Jigjiga University-Directorate of Research and Community Service (JJU-DRCS) and all college deans and department heads were informed about this study. Participation of the students in this study was voluntarily and written consent was obtained from each participant before data collection. Students were informed that questionnaires are anonymous and confidential. Names of the students were not recorded anywhere on the questionnaire and measures taken to ensure the respect, dignity and freedom of each student participated in the study.

\section{Results and Discussion}

\section{Background Characteristics of the Respondents}

A total of 648 questionnaires were distributed and 600 of them were appropriately filled with the response rate of $92.6 \%$. Data were collected from $2^{\text {nd }}$ and above year students (we assumed that $1^{\text {st }}$ year students may have different background since they join the University recently) of three colleges namely college of Medicine and Health sciences, college of social sciences, and college of engineering and technology which were randomly selected from eight colleges under the University. As it was shown in the table below, from the total of 600 study participants $281(46.8 \%)$ were $2^{\text {nd }}$ year, $176(29.3)$ were $3^{\text {rd }}$ year, $143(23.8) 4^{\text {th }}$ year and above, (411 (68.5) were in the age range of 22-25 years, $396(66 \%)$ were male students. Majority of them were Muslim, 325 (54.2\%), and 533 (88.8\%) of them were single (Table 1).

Table 1: Socio demographic characteristics of the respondents in JJU, 2014.

\begin{tabular}{|c|c|c|}
\hline Variables & Frequency & Percent \\
\hline \multicolumn{3}{|c|}{ Age } \\
\hline $18-21$ & 176 & 29.3 \\
\hline $22-25$ & 411 & 68.5 \\
\hline$>25$ & 13 & 2.2 \\
\hline Total & 600 & 100 \\
\hline \multicolumn{3}{|c|}{ Year of study } \\
\hline 2nd & 281 & 46.8 \\
\hline $3 r d$ & 176 & 29.4 \\
\hline 4th and above & 143 & 23.8 \\
\hline total & 600 & 100 \\
\hline \multicolumn{3}{|c|}{ Sex } \\
\hline male & 396 & 66 \\
\hline female & 204 & 34 \\
\hline total & 600 & 100 \\
\hline \multicolumn{3}{|c|}{ Religion } \\
\hline Muslim & 325 & 54.2 \\
\hline Orthodox & 160 & 26.7 \\
\hline protestant & 99 & 16.5 \\
\hline other & 16 & 2.7 \\
\hline total & 600 & 100 \\
\hline
\end{tabular}




\section{Issues Related to Alcohol Drinking}

As it was summarized below in table 2, 164 (27.3\%) of the students have experienced alcohol drinking in their lifetime while $110(18.3 \%)$ of them were current drinkers. Among the students who drink 60 (36.6\%) of them started drinking at the age range of $16-20$ years while about $10 \%$ of them responded that they were engaged in drinking after 20 years of age and about half of them responded they started alcohol drinking during the first 10 years of their life (Table 2).

Table 2: Summary of alcohol drinking status of the study participants in JJU, 2014.

\begin{tabular}{|c|c|c|}
\hline Variables & Frequency & Percent \\
\hline \multicolumn{3}{|c|}{ Ever drink alcohol } \\
\hline Yes & 164 & 27.3 \\
\hline No & 436 & 72.7 \\
\hline total & 600 & 100 \\
\hline \multicolumn{3}{|c|}{ At what age you started } \\
\hline$<5$ years & 25 & 15.2 \\
\hline 5-10 & 56 & 34.1 \\
\hline $11-15$ & 7 & 4.3 \\
\hline $16-20$ & 60 & 36.6 \\
\hline$>20$ & 16 & 9.8 \\
\hline Total & 164 & 100 \\
\hline \multicolumn{3}{|c|}{ Drink last 12 month } \\
\hline Yes & 110 & 67.1 \\
\hline No & 54 & 32.9 \\
\hline Total & 164 & 100 \\
\hline \multicolumn{3}{|c|}{ How often do you drink } \\
\hline Every day & 6 & 3.7 \\
\hline 4-6 per week & 16 & 9.8 \\
\hline 2-3 per week & 30 & 18.3 \\
\hline $2-3$ per month & 112 & 68.3 \\
\hline Total & 164 & 100 \\
\hline \multicolumn{3}{|c|}{ What did you drink in 12 month } \\
\hline Beer & 112 & 68.3 \\
\hline Local arake & 17 & 10.4 \\
\hline Local tela & 23 & 14 \\
\hline Local tej & 3 & 1.8 \\
\hline Wine & 9 & 5.5 \\
\hline Total & 164 & 100 \\
\hline \multicolumn{3}{|c|}{ With whom you drink } \\
\hline Friends & 123 & 75 \\
\hline Alone & 22 & 13.4 \\
\hline With bar ladies & 6 & 3.7 \\
\hline With sexual partner & 13 & 7.9 \\
\hline Total & 164 & 100 \\
\hline \multicolumn{3}{|c|}{ At what time you drink } \\
\hline Evening & 38 & 23.2 \\
\hline Weekends & 38 & 44.5 \\
\hline Holydays & 73 & 9.1 \\
\hline Any invitation & 15 & 100 \\
\hline Total & 164 & \\
\hline
\end{tabular}




\section{Global Journal of Addiction \& Rehabilitation Medicine}

\begin{tabular}{|c|c|c|}
\hline \multicolumn{2}{|c|}{ What do you do after drink } & 33.5 \\
\hline Sleep & 55 & 37.8 \\
\hline Dance & 62 & 7.9 \\
\hline Hang out with friends & 13 & 20.7 \\
\hline Have a sex & 34 & 100 \\
\hline Total & 164 & \\
\hline
\end{tabular}

Factors Associated to Drinking Alcohol among Jigjiga University Students

In our study among the independent variables, being year 3 , and 4 and above year of study, age 22-25, being male sex, having drunker friend, being smoker, chat chewer and having history of drug use are significantly associated to the dependent variable look at Table 3. Accordingly, the odds of drinking alcohol was higher in year $3 \& 4$ and above students compared with those at $2^{\text {nd }}$ year students, $(\mathrm{COR}=20.20 ; 95 \% \mathrm{CI}:(11.30,36.20)] \&$ [COR=2.48;95\%CI $(1.58,3.90)]$. The odds of drinking alcohol was also higher among students with 22-25 compared to those with ager 18-21, [COR=5.18; 95\% CI: $(1.61,16.67)]$, and the likelihood of drinking alcohol was higher among male students, [COR $=2.82 ; 95 \%$ CI: $(1.83,4.36)]$. Students with drinker friends were at higher risk of drinking alcohol COR=5.86; 95\% CI: $(3.89$, 8.81)] when compared with those who don't have drinker friend.

Table 3: Table showing factors associated to drinking alcohol among the study participants in JJU, 2014.

\begin{tabular}{|c|c|c|c|c|}
\hline Characteristic & Frequency & Alcohol (\%) & $\operatorname{COR}(95 \% \mathrm{CI})$ & AOR $(95 \% \mathrm{CI})$ \\
\hline \multicolumn{5}{|c|}{ Year of study } \\
\hline $2^{\text {nd }}$ & 281 & $18(6.4)$ & 1 & 1 \\
\hline $3^{\text {rd }}$ & 176 & $63(35.8)$ & $20.20(11.298,36.159)$ & $5(2.13,10.25)$ \\
\hline $4^{\text {th }}$ and above & 143 & $83(58)$ & $2.48(1.577,3.903)$ & $4.92(1.98,12.14)$ \\
\hline \multicolumn{5}{|c|}{ Age } \\
\hline $18-21$ & 176 & $25(14.2)$ & 1 & 1 \\
\hline $22-25$ & 411 & $133(32.3)$ & $5.177(1.607,16.67)$ & $4.97(0.66,37.47)$ \\
\hline$>25$ & 13 & $6(46.1)$ & $1.792(0.591,5.436)$ & $4.05(0.70,23.26)$ \\
\hline \multicolumn{5}{|c|}{ Sex } \\
\hline Male & 396 & $133(35.6)$ & $2.822(1.826,4.36)$ & $71.91(21.76,237.69)$ \\
\hline Female & 204 & $31(15.2)$ & 1 & 1 \\
\hline \multicolumn{5}{|c|}{ Religion } \\
\hline Orthodox & 160 & $73(45.6)$ & 1 & \\
\hline Muslim & 325 & $36(11.1)$ & $4.80(0.85,14.03)$ & \\
\hline Protestant & 99 & $49(49.5)$ & $0.612(0.207,1.814)$ & \\
\hline Other & 16 & $6(37.5)$ & & \\
\hline \multicolumn{5}{|c|}{ Marital status } \\
\hline Single & 533 & $152(28.5)$ & 1 & \\
\hline Married & 38 & $3(7.9)$ & $0.752(0.204,2.740)$ & \\
\hline Divorced & 16 & $6(37.5)$ & $3.50(0.610,20.09)$ & \\
\hline Widowed & 13 & $3(23.1)$ & $0.50(0.09,2.577)$ & \\
\hline \multicolumn{5}{|c|}{ Have Drunker family } \\
\hline Yes & 145 & $42(29)$ & $1.13(0.735,1.685)$ & \\
\hline No & 455 & $122(26.8)$ & 1 & \\
\hline \multicolumn{5}{|c|}{ Have Drunker friend } \\
\hline Yes & 141 & $80(56.7)$ & $5.855(3.891,8.810)$ & $33.25(11,100)$ \\
\hline No & 459 & $84(18)$ & 1 & 1 \\
\hline \multicolumn{5}{|c|}{ Ever chew chat } \\
\hline Yes & 200 & $87(43.5)$ & $3.23(2.222,4.695)$ & $2.78(1.15,6.83)$ \\
\hline No & 400 & $77(19.25)$ & 1 & 1 \\
\hline \multicolumn{5}{|c|}{ Ever Smoke cigarette } \\
\hline
\end{tabular}


Global Journal of Addiction \& Rehabilitation Medicine

\begin{tabular}{|c|c|c|c|c|}
\hline Yes & 87 & $48(55.2)$ & $4.212(2.631,6.743)$ & $4.45(1.04,19.08)$ \\
\hline No & 513 & $116(22.6)$ & 1 & 1 \\
\hline \multicolumn{5}{|c|}{ Ever take any drug } \\
\hline Yes & 76 & $43(56.6)$ & $4.340(2.640,7.134)$ & $11.55(3.28,40.75)^{*}$ \\
\hline No & 524 & $121(23.1)$ & 1 & 1 \\
\hline
\end{tabular}

*Significant at $\mathrm{P}<0.05$

As witnessed in Table 3 below, those students who ever chew chat were with higher odds of drinking alcohol COR=3.23; $95 \%$ CI: $(2.22,4.70)]$ when compared with those never chew chat. Those students who ever smoke cigarette were more likely to drink alcohol COR=4.212; 95\% CI: $(2.63,6.74)]$ comparing with non smokers .Being drug user was risk factor for alcoholism as those use drug were at higher risk for drinking alcohol COR $=4.340 ; 95 \%$ CI: $(2.640,7.134)]$.

\section{Discussion}

In this study, we found the prevalence of ever drinking alcohol to be $27.3 \%$ and the prevalence of current drinking alcohol was $18.3 \%$. Current prevalence is higher than the result of studies conducted among adolescent in Iran (15.1\%) [9], among Debra Markos poly technique students (13.4\%) [10], among Adigirat University students (8.7\%) [11], among University students in Sudan (2.7\%) [12] the possible reasons for the difference could be geographical locations, difference in times of study and availability of alcohol factory at near distance. The finding of this study was slightly lower than finding of a study conducted in Bishoftu (Ethiopia) (22.8\%) [13], Italy (42.2\%) [14], South Africa (70\%) [15], Kenya (51.9\%) [16], Ginnir town, (31.2\%) [17], Woreta town (Ethiopia) (40.9\%) [18], Dilla University (Ethiopia) (64.7\%). This difference may be contributed by the difference in the study areas, availability of the source in the area and the attitude of the local community toward alcohol drinking and the timing of the study.

The possible reasons for the difference could be cold weather conditions (in the case of Ginnir, Woreta), proximity to the capital city and time difference. This study showed that there was a positive relationship between alcohol drinking and students year of study. Accordingly, the odds of drinking alcohol was 3.7 times higher among students on their $3^{\text {rd }}$ year of study compared with their juniors, $(\mathrm{AOR}=3.7(95 \% \mathrm{CI}=2.40,16)$, and this association became stronger when we compare participants in year four and above with those at 2nd year, (AOR=4.92(95\% $\mathrm{CI}=1.98,12.14)$. This study also revealed that being male is positively associated to drinking alcohol; the odds of drinking alcohol was about 2 times higher among male students compared with female students, AOR=2.12 95\% CI=1.89,6. 69).

The finding of this study also revealed that having drinker friend, ever chew chat, ever smoke cigarette, and ever tried any drug were significantly associated with drinking alcohol, AOR=33.25 $95 \%$ CI=11),100, OR=2.78, 95\% CI=1.15,6.83),
$\mathrm{AOR}=4.45,95 \% \mathrm{CI}=1.04,19.08), 11.55(3.28,40.75)$, respectively. This positive relationship agrees with the finding of similar study conducted in Ethiopia among Addis Ababa University medical students in which male sex were significantly associated with alcohol drinking (AOR=2.14, 95\% $\mathrm{CI}=1.22,3.76)$. The finding of our current study also comparable with the finding of the study which was conducted among AAU medical students in which those students having a drunker friend, having a friend who smokes, and having friend who chew chat, $\mathrm{AOR}=2.47,3.89$, and 15.11 respectively.

\section{Conclusion}

The prevalence of alcohol use among undergraduate students of Jigjiga University is significantly high, students' year of study, male sex, having a friend who use the substance especially alcohol, and using one substance were predisposing factors to alcohol use. It is therefore recommended that University top management should strengthen its collaboration with city municipality to move far drinking houses from the compound. There should be a regular awareness creation program for all students regarding to the health, economical, academicals and social burdens of being a drinker. It will be good to have a recreation centre within the compound of the university to minimize students' movement out of the campus. Researchers may also plan to do a triangulated study to investigate the root causes in detail.

\section{Authors' Contribution}

DS, TK and GF participated in designing the study, data collection, reviewing and editing the final draft of the manuscript. DS, LA performed statistical analysis and wrote the manuscript. All authors read and approved the final manuscript.

\section{Acknowledgement}

We would like to acknowledge Jigjiga University who funded this paper and also we are grateful to our study participants, data collectors and supervisors for their unreserved participation.

\section{References}

1. Odejide AO (2006) Status of Drug Use/Abuse in Africa: A Review. International Journal of Mental Health and Addiction 4(2): 87-102.

2. Volkow ND, Li TK (2005) Drugs and alcohol: Treating and preventing abuse, addiction and their medical consequences. Pharmacology and Therapeutics 108(1): 3-17.

3. Wechsler H, Rigotti NA, Glendhill Hoyt J, Lee H (1998) Increased levels of cigarette use among college students - a cause for national concern. JAMA 280(19): 1673-1678. 
4. Kassaye M, Sherief TH, Ghimja F, Teklu F (1999) Drug use among school students in Addis Ababa and Butajira. Ethiopian Journal of Health Development 13(2): 101-106.

5. Dhanookdhary AM, Gomez AM, Khan R, Lal A, Muray D, et al. (2010) Substance use among university students at Sant Augstien campus of the University of the West India. West Indian Medical Journal 59(6): 641-649.

6. Andargachew Kassa, Serawit Deyno (2014) Prevalence and Determinants of Active and Passive Cigarette Smoking among undergraduate students at Hawassa University, Hawassa, Ethiopia. Journal of Tropical Diseases \& Public Health 2(4): 145.

7. Wakgari Deressa, Aklilu Azaz (2011) Substance use and its predictors among undergraduate medical students of Addis Ababa University in Ethiopia. BMC Public Health 11:660.

8. Azam B, Zeynab H, Raza M, Sahrnas N, Eesa M (2013) Alcohol and Drug use Prevalence and Factors Associated with the Experience of Alcohol use in Iranian Adolescents. Iranian Red Cresent Medical Journal 15(3):212-217

9. Tesfahun A, Gebeyaw T, Girmay T (2013) Assessment of Substance Abuse and Associated Factors among Students of DebreMarkos Poly Technique College in Debre Markos Town, East Gojjam Zone, Amhara Regional State, Ethiopia.

10. Tilahun Belete Mossie, Gebrewahd Bezabh Gebre Michael, Ashenafi Damte Ayel (2015) Magnitude of Psychoactive Substance Abuse among University Students, Adigrat, North Ethiopia: Cross Sectional Study. Journal of Psychiatry 18 (4): 1000281.

11. Tarij O, Catherine V, Alaa A, Hala M, Fatima A, et al. (2016) Epidemiology of substance use among university students in Sudan. Journal of addiction. 2016(2016): 8.
12. Tadesse Gudeta, Eshetu Mulisa (2015) Prevalence Of Substance Abuse and its Associated Factors Among The Students Of The Rift Valley University College, Bishoftu, East Ethiopia. medicinskarevija medical review 7(1): 033-040.

13. Andrea Poscia, Paolo Parente, Emanuela Maria Frisicale, Adele Anna Teleman, Chiara De Waure, et al. (2015) Risky behaviours among university students in Italy. Ann Ist Super Sanità 51(2): 111-115.

14. Supa Pengpid, Karl Peltzer, Hendry van der Heever, Linda Skaal (2013) Screening and Brief Interventions for Hazardous and Harmful Alcohol Use among University Students in South Africa: Results from a Randomized Controlled Trial. International Journal of Environmental Research and Public Health 10(5): 2043-2057.

15. Lukoye Atwoli, Prisca A Mungla, Moses N Ndung'u, Kiende C Kinoti, Evans M Ogot (2011) Prevalence of substance use among college students in Eldoret, western Kenya. BMC Psychiatry 11:34.

16. Ahmed Yasin Mohammed (2014) Assessment of substance use and associated factors among high school and preparatory school students of Ginnir Town, Bale Zone, Southeast Ethiopia. American Journal of Health Research 2(6): 414-419.

17. Anteneh Messele Birhanu, Telake Azale Bisetegn, Solomon Meseret Woldeyohannes (2014) High prevalence of substance use and associated factors among high school adolescents in Woreta Town, Northwest Ethiopia: multi-domain factor analysis. BMC Public Health 14: 1186 .

18. Moges Tadesse (2014) Substance abuse and sexual HIV-risk behaviour among Dilla University students, Ethiopia. International Research Journal 5(9): 368-374.
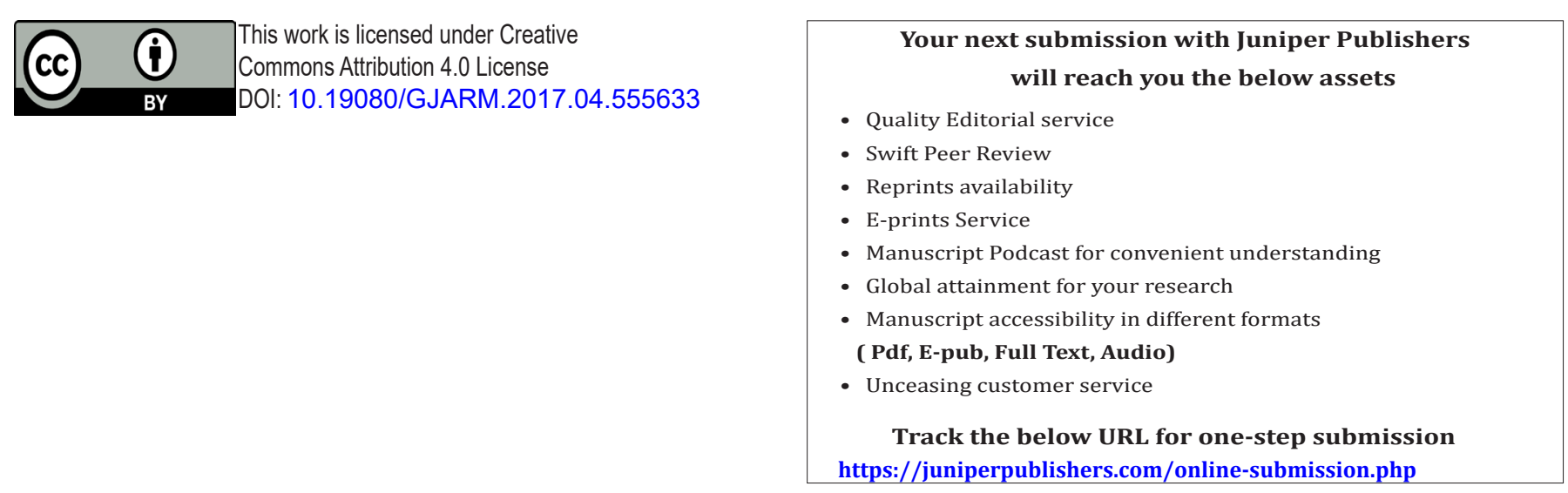